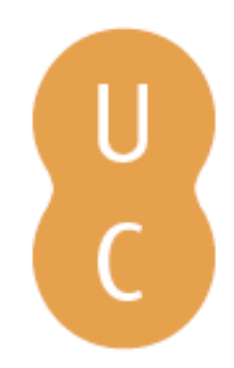

\title{
nommalina
}

\section{A mediação nos cursos EFA: dados de um estudo sobre a actividade profissional dos mediadores}

Autor(es): $\quad$ Preguiça, Cláudia Santos; Alcoforado, Luís

Publicado por: Imprensa da Universidade de Coimbra

URL

persistente: URI:http://hdl.handle.net/10316.2/31269

DOI: $\quad$ DOI:http://dx.doi.org/10.14195/978-989-26-0228-8_11

Accessed : $\quad$ 26-Apr-2023 15:10:56

A navegação consulta e descarregamento dos títulos inseridos nas Bibliotecas Digitais UC Digitalis, UC Pombalina e UC Impactum, pressupõem a aceitação plena e sem reservas dos Termos e Condições de Uso destas Bibliotecas Digitais, disponíveis em https://digitalis.uc.pt/pt-pt/termos.

Conforme exposto nos referidos Termos e Condições de Uso, o descarregamento de títulos de acesso restrito requer uma licença válida de autorização devendo o utilizador aceder ao(s) documento(s) a partir de um endereço de IP da instituição detentora da supramencionada licença.

Ao utilizador é apenas permitido o descarregamento para uso pessoal, pelo que o emprego do(s) título(s) descarregado(s) para outro fim, designadamente comercial, carece de autorização do respetivo autor ou editor da obra.

Na medida em que todas as obras da UC Digitalis se encontram protegidas pelo Código do Direito de Autor e Direitos Conexos e demais legislação aplicável, toda a cópia, parcial ou total, deste documento, nos casos em que é legalmente admitida, deverá conter ou fazer-se acompanhar por este aviso.

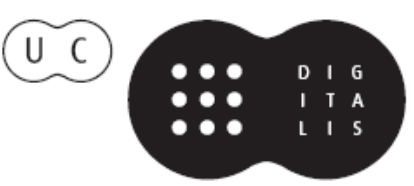




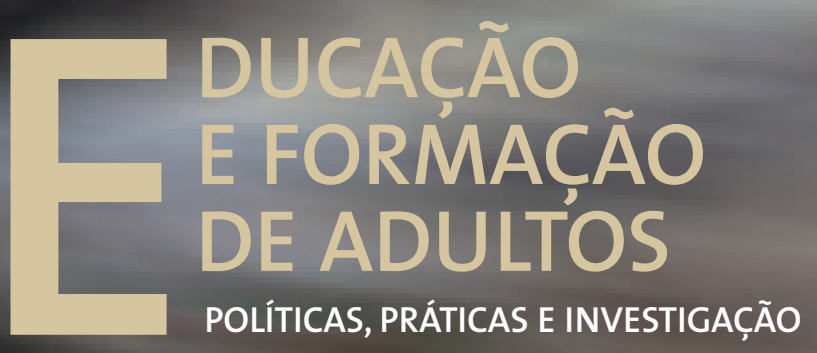

Luís Alcoforado • Joaquim Armando G. Ferreira António Gomes Ferreira • Margarida Pedroso de Lima Cristina Vieira • Albertina L. Oliveira • Sónia Mairos Ferreira 


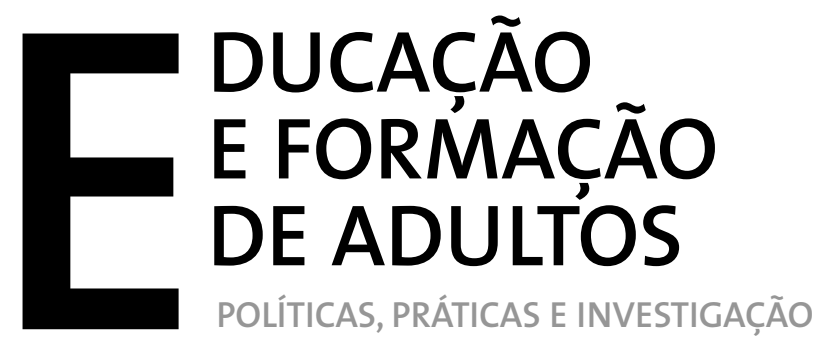

Luís Alcoforado • Joaquim Armando G. Ferreira António Gomes Ferreira - Margarida Pedroso de Lima Cristina Vieira • Albertina L. Oliveira • Sónia Mairos Ferreira 
EDIÇÃo

Imprensa da Universidade de Coimbra

URL: http://www.uc.pt/imprensa_uc

Vendas online: http://www.livrariadaimprensa.com

CONCEPÇÃO GRÁFICA

António Barros

Pré-Impressáo

SerSilito-Empresa Gráfica, Lda

EXECUÇÃo GRÁFICA

SerSilito-Empresa Gráfica, Lda

ISBN

978-989-26-0136-6

DePósito LEgaL

$340309 / 12$ 



\title{
A Mediaçáo nos Cursos EFA: \\ DAdOS DE UM ESTUdo SOBRE A ACTIVIDAdE PROFISSIONAL dOS MEdiadores
}

\author{
Cláudia Santos Preguiça \\ Luís Alcoforado \\ Universidade de Coimbra
}

\section{Introdução}

O primeiro contacto que tivemos com os Cursos de Educação e Formação de Adultos (EFA) e com toda a filosofia que lhes está inerente, constituiu cronologicamente o primeiro impulso que nos direccionou para a problemática da mediaçáo. Estes cursos passaram a constituir, pela primeira vez, no nosso país, uma oferta institucionalizada de educaçáo e formação de adultos, integrada, flexível, táo desescolarizada quanto possível, que considera todos os aspectos da vida das pessoas, das suas características e dos seus adquiridos, adequando as novas aprendizagens às experiências de aprendizagem já existentes e ao mundo familiar, profissional e social dos indivíduos.

O/a Mediador/a surge, no âmbito desta oferta de educação e formação como uma profissionalidade emergente, vocacionada para uma promoção contínua da autonomia pessoal e social dos/as formandos/as, através da construção de um percurso de criação de sentido destinado a suportar a integração das aprendizagens na vida quotidiana. A mediação pessoal e social, mesmo na educação e na formação, resulta, contudo de longínquas e respeitáveis heranças. Sem preocupação de sermos exaustivos, basta recordar contributos teóricos bem conhecidos, para encontrarmos um entendimento de mediador como aquele que estabelece uma relação entre o sujeito e o objecto da mediação, que será, neste caso, a aprendizagem (Vygotsky, 1988), tendo em conta que esta é entendida como um processo interno, controlado pelo sujeito e que implica o empenhamento global da pessoa na interacção com o meio, visando uma transformaçáo construtiva (Rogers, 1983). Por seu turno, Fuerstein (1994) descreve as interacções de mediação como uma necessidade humana de transmissão cultural entre geraçóes, sugerindo que o Mediador deve dirigir a sua actividade num equilíbrio entre três pólos: situar a pessoa que aprende face a si própria, face aos outros e face às suas formas de acção. Desta forma, ele consegue o objectivo geral da mediação, ao contribuir para harmonizar o ser humano consigo mesmo e com os outros, no contexto onde todos interagem, em todas as dimensóes da sua vida pessoal e social.

Assim entendida, a mediação pressupóe uma relação de acompanhamento (Lietard \& Pineau, 1998) que se deverá alargar a todo o processo de ensino-aprendizagem, começando com a tomada de consciência dos adquiridos precedentes, das características pessoais e dos contextos, da relação entre os diferentes agentes do processo, de construção e implementação de projectos pessoais e de criação de sentido para as novas aquisiçôes. A mediação tem, então, um papel de absoluta centralidade, na substituição de modelos mais tradicionais em uso na educação e formação de adultos, por práticas educativas de filiação andragógica e transformadora, onde as pessoas passam a ser o elemento central de todo o processo educativo, englobando os novos saberes e competências na construçáo de projectos de mudança, ao mesmo tempo desafiantes e realistas. 
Tendo em conta o facto de se tratar de uma profissionalidade emergente, enquadrada num conjunto de políticas recentes, torna-se necessário e pertinente analisar e compreender como a Mediaçáo é realizada no âmbito das práticas EFA, neste momento, em Portugal, reflectindo sobre estas práticas e os respectivos quadros de suporte, procurando, na medida da modéstia de uma investigação desta natureza, deixar algumas reflexóes e contributos para a optimizar.

Para melhor percebermos o que se espera da Mediação de Cursos EFA em Portugal realizámos uma análise detalhada do artigo 25 da portaria no 230/2008, que regulamenta a acção do Mediador Pessoal e Social de Cursos EFA. Desta observaçáo concluímos que a portaria enuncia, para este "elemento da equipa técnico-pedagógica", funçóes muito abrangentes, sendo pouco clara relativamente às actividades a desenvolver num Curso EFA e pouco esclarecedora relativamente às habilitaçóes que este profissional deve possuir para o desempenho destas actividades.

Continuámos a nossa demanda com uma incursão pelo site da Agência Nacional para a Qualificação (ANQ) e percebemos que aqui, entre vários documentos dispersos, é possível encontrar outras orientaçóes sobre o papel do Mediador e sobre as suas competências e funçôes, a saber:
a) Escutar as necessidades, interesses e motivaçôes dos participantes e adaptar as actividades às condiçóes do grupo;
b) Ser capaz de proporcionar aos participantes na formação de um ambiente de confiança e empatia;
c) Orientar a reflexão e apoiar o processo de consciencialização de cada um dos formandos;
d) Facilitar o processo de formação, promovendo atitudes e comportamentos que incentivem a participação activa dos adultos na construção e regulação do projecto pedagógico;
e) Favorecer a aplicação/utilização imediata das aprendizagens realizadas e das competên- cias adquiridas;
f) Fornecer ao adulto, o mais cedo possivel, feedback da sua progressão no processo formativo. ${ }^{1}$

A análise da legislação e a procura de informação oficial, não só não respondeu completamente às nossas indagaçóes, como nos levantou ainda mais questóes. Se é verdade que se afirma que o/a mediador/a pode colaborar na constituição do grupo de formação, deve garantir o acompanhamento dos/as formandos/as, deve dinamizar a equipa de formação e assegurar a articulação entre esta e o grupo de formandos/as; se também é certo que lhe é permitida a animação do módulo de Aprender com Autonomia e da área de Portefólio Reflexivo de Aprendizagens; mesmo assim sobram um conjunto de possibilidades e interrogaçóes que, em nosso entender, é do maior interesse procurar perceber: Qual será a necessidade da figura do Mediador no papel das políticas de acção dos Cursos EFA, segundo a perspectiva dos Coordenadores e dos Mediadores? Qual será o perfil desejável do Mediador por parte das entidades empregadoras? Por quem é seleccionado, e qual é a formação base e características pessoais que mais se enquadram dentro do perfil pretendido? Quais são as principais funçóes do Mediador, segundo o ponto de vista dos Coordenadores e dos Mediadores? Quais são os objectivos centrais de algumas das actividades especificamente atribuídas aos Mediadores como, por exemplo, as unidades Aprender com Autonomia (AA)

\footnotetext{
1 Disponível em: http://www.anq.gov.pt/default.aspx, consultado a 10/01/2010.
} 
e Portefólio Reflexivo de Aprendizagens (PRA)? Será que as 40 horas definidas na legislação para AA e as 85 horas definidas para o PRA serão suficientes? Quais são as metodologias utilizadas no estabelecimento de relações interpessoais/promoção de melhor ambiente entre o Mediador os Formandos e os Formadores, entre os Formadores e os Formandos e entre os próprios Formandos no processo de Mediação? Será que existe uma confluência entre aquilo que a instituição espera do papel do Mediador, e aquilo que pensam sobre a sua actividade? Quais são os parâmetros de avaliação do trabalho do Mediador? Será que a legislação acerca desta profissão é suficiente e adequada? Como é que os Mediadores identificam e reconhecem o seu trabalho?

\section{Questóes de investigação}

Procurando sistematizar este alargado conjunto de interrogaçóes e recorrendo aos quadros teóricos de suporte à educação e formação de adultos e, por extensão, à actividade de mediação, procuramos um fio condutor para a pesquisa a efectuar, estabilizando na formulação das seguintes questóes de investigação:

- Quais as actividades profissionais dos/as Mediadores/as e a importância da figura da Mediação na perspectiva dos/as próprios/as Mediadores/as e dos/as Coordenadores/ as de Formação de organizações com diferentes culturas formativas;

- Que metodologias são utilizadas no estabelecimento das diferentes relaçóes que se vão desenvolvendo ao longo do processo de Mediação;

- Até que ponto existe convergência entre aquilo que é previsto na legislação, o que a instituição espera do dos/as Mediadores/as e a forma como estes percepcionam o desenvolvimento da sua profissionalidade.

\section{Metodologia}

Assumindo que podem existir diversos padrôes/metodologias profissionais dentro do panorama nacional e uma vez que se trata de uma investigaçáo sobre uma profissáo recente em Portugal, pensámos que seria pertinente recolher dados de entidades de formação com diferentes características e formas de trabalho, no sentido de podermos tomar consciência da possível interferência causada pelas opçôes de organização e gestão desses contextos. Para avaliar a importância da Mediação, dimensionar a sua profissionalidade, identificar os procedimentos pelos quais estes profissionais são avaliados, o trajecto desta profissão, etc... foi elaborado um conjunto de questóes, com vista à realização de entrevistas a Coordenadores/as e Mediadores/as, em centros de formação e escola públicas, todos do distrito de Aveiro. Após análise das possibilidades optou-se por incluir um centro pertencente à rede do Serviço Público de Formação Profissional, uma Empresa Privada de Formação e uma Escola Pública. A amostra final ficou constituída por duas Coordenadoras e um Coordenador e por cinco Mediadoras, que acederam a conceder uma entrevista aberta, apenas orientada por questóes de natureza geral, procurando centrar as respostas nos temas da nossa investigação. 


\section{Resultados}

Após transcrição e leitura cuidada das entrevistas, procedemos à análise de conteúdo, confrontando-as com os respectivos guiôes e os objectivos da investigação. Esta análise permitiu-nos comparar as respostas e avaliar dentro da sua complexidade, as semelhanças e diferenças, que passamos de seguida a apresentar.

Relativamente à primeira questão, que diz respeito à necessidade da figura do Mediador nos Cursos EFA, os dados revelaram-nos que todos os sujeitos entrevistados, (Coordenador/as e Mediadoras) consideram o Mediador um elemento essencial dos Cursos EFA, enquanto dinamizador de aprendizagens e elemento pacificador e aglutinador nos grupos de formação. Todos sem excepção defendem que o Mediador é um elemento que teria que existir obrigatoriamente, mesmo que a legislação não o exigisse.

No que respeita à contratação do Mediador, com excepção da escola que contrata por concurso público com base em critérios de graduação profissional e tempo de serviço, concluímos que nas outras instituiçóes de educação/formação a sua contratação é efectuada pelos Coordenadores. Apesar destes profissionais afirmarem preferir contratar Mediadores da área das Ciências Sociais e Humanas, mais concretamente da Sociologia, Ciências da Educação ou Psicologia, percebemos pela análise do seu discurso que esta preferência náo é normativa e que já ocorreu contratarem profissionais de outras áreas de conhecimento, a título de exemplo: “(...) tive uma Mediadora que não era das Ciências Sociais, que era Professora Primária (...)”. Podemos então concluir que, há falta de directrizes específicas que regulamentem a contratação dos Mediadores, estes são recrutados segundo sensibilidades pessoais de estabelecimento de empatia com o Coordenador que, nestes processos, representa a Instituição. Relativamente à escola qualquer professor de qualquer área de conhecimento pode assumir o papel de Mediador. A respeito desta questão (perfil desejável) os/as Mediadores/as na sua maioria confirmam que o facto de terem formação de base em Ciências Sociais, estas lhes fornecem ferramentas fundamentais para exercerem Mediação, excepção para uma das Mediadoras da Instituição de Formação Pública: “(...) eu acho que a Mediação pode ser feita por todas as pessoas com as mais variadas qualificaçôes (...)".

Os Coordenadores das instituiçóes de formação consideram muito relevante a existência de formação contínua/reciclagem de conhecimentos, para os Mediadores, deixando consideraçóes sobre como é que poderiam ser estruturadas acçóes de formação para estes profissionais, com o objectivo de renovaçáo e aquisiçáo de novas competências e conhecimentos. A partir dos elementos estudados, podemos afirmar que para estes profissionais (Coordenador/as e Mediadoras) as "reciclagens" de conhecimentos são importantes, sendo que uma das Mediadoras da Instituição Privada de Formação vai fazer mais formação, porque sente necessidade de se "especializar um bocadinho mais". Julgamos ser importante referir que o/as Coordenador/as, principalmente o Coordenador da Instituição Privada de Formação, defendem que a formação ministrada deverá ter conteúdos mais práticos, sem obviamente esquecer os quadros teóricos, mas enriquecidos comos contributos das actividades práticas.

No que respeita às características pessoais que os Mediadores devem demonstrar, os participantes da investigação sugeriram sensibilidade, rigor, flexibilidade e capacidade de adaptação, como as quatro características fundamentais que um Mediador deve possuir. Já em relação às principais actividades do Mediador pode concluir-se que estas vão ao encontro, de uma forma geral, das funçóes previstas pela legislação e pela ANQ, com 
algumas adequaçóes ao contexto conforme seria expectável. Entre os centros verificamos algumas diferenças que julgamos dignas de nota, podendo referir-se, por exemplo, que na Instituição de Formação Pública e na Escola as Mediadoras trabalham a tempo parcial e na Instituição de Formação Privada trabalham a tempo inteiro.

Apresentamos de seguida (cf. Quadro 1) um quadro que sintetiza as principais actividades desempenhadas pelas Mediadoras, tal como são enunciadas por elas próprias.

Quadro 1. Actividades desempenhadas pelo Mediador no Centro de Formação/Escola

\begin{tabular}{|c|c|}
\hline Sujeito & Principais Actividades \\
\hline $\begin{array}{l}\text { Coordenadora } 1 \\
\text { (Instituiçáo Pública } \\
\text { de Formaçáo) }\end{array}$ & $\begin{array}{l}\text { Coordenação, gestão de conflitos, dinamização das reuniōes da equipa formativa, } \\
\text { controle da assiduidade de Formandos e Formadores, levantamento das necessidades } \\
\text { dos materiais para a formação, dossier técnico-pedagógico. }\end{array}$ \\
\hline $\begin{array}{l}\text { Coordenador } 2 \\
\text { (Instituiçáo Privada } \\
\text { de Formaçáo) }\end{array}$ & Coordenar/gerir o curso, estabelecer a ligação entre Formandos e Formadores. \\
\hline $\begin{array}{l}\text { Coordenadora } 3 \\
\text { (Escola Pública) }\end{array}$ & A Coordenadora apenas afirmou que se regia pela legislação. \\
\hline $\begin{array}{l}\text { Mediadora } 1 \\
\text { (Instituiçáo Pública } \\
\text { de Formaçáo) }\end{array}$ & $\begin{array}{l}\text { Cronogramas, dossier técnico-pedagógico, reuniōes, actas, leccionar Aprender com } \\
\text { Autonomia e PRA. }\end{array}$ \\
\hline $\begin{array}{l}\text { Mediadora } 2 \\
\text { (Instituiçáa Pública } \\
\text { de Formação) }\end{array}$ & $\begin{array}{l}\text { Cronogramas, justificar faltas, informar o Coordenador de questôes do grupo, } \\
\text { reuniōes, actas, fazer trocas entre Formadores, inserçáo de dados no SIGO, entregar } \\
\text { os vouchers dos computadores aos Formandos, certificação dos Formandos, fazer o } \\
\text { dossier técnico-pedagógico, leccionar Aprender com Autonomia e PRA. }\end{array}$ \\
\hline $\begin{array}{l}\text { Mediadora } 3 \\
\text { (Instituiçáo Privada } \\
\text { de Formaçáo) }\end{array}$ & $\begin{array}{l}\text { Fazer o dossier técnico-pedagógico, leccionar Aprender com Autonomia, seleccionar } \\
\text { Formandos e Formadores, fazer trocas de horários entre Formadores, controlar as } \\
\text { faltas dos Formandos e Formadores, inserir dados no SIGO e no SIF, preparar } \\
\text { avaliaçóes, fazer todo o trabalho burocrático. }\end{array}$ \\
\hline $\begin{array}{l}\text { Mediadora } 4 \\
\text { (Instituiçáo Privada } \\
\text { de Formação) }\end{array}$ & $\begin{array}{l}\text { Fazer o dossier técnico-pedagógico, leccionar Aprender com Autonomia e PRA, } \\
\text { seleccionar Formandos e Formadores, controlar as faltas dos Formandos e Forma- } \\
\text { dores, acompanhamento dos Formandos, enviar todos os meses para o Fundo Social } \\
\text { Europeu um relatório das faltas dos Formandos e dos Formadores e da execuçáo } \\
\text { física do curso, fazer todo o trabalho burocrático. }\end{array}$ \\
\hline $\begin{array}{l}\text { Mediadora } 5 \\
\text { (Escola Pública) }\end{array}$ & $\begin{array}{l}\text { Trabalho administrativo, faltas, planificaçóes, reunióes, actas, dossier técnico- } \\
\text { pedagógico. }\end{array}$ \\
\hline
\end{tabular}

Podemos verificar que segundo as directrizes da Instituição Pública de Formação e da Escola as actividades das Mediadoras restringem-se ao nível administrativo e burocrático, dando pouca relevância à mediatização da aprendizagem. As Mediadoras não participam no processo de selecção dos formandos, acompanhando-os parcelarmente e realizando, desta forma, um processo pouco profundo de identificação de competências. No centro de formação privado os/as Mediadores/as trabalham a tempo inteiro e acompanham permanentemente a evolução do curso, intervindo na selecção dos formandos/as, estando sempre presentes na instituição para o caso de serem solicitadas, disponibilizando um horário de atendimento para os formandos/as e contribuindo para solucionar as suas questóes/ problemas de forma individualizada.

Ficou claro que o facto de algumas Mediadoras trabalharem a tempo parcial em várias instituiçôes interfere directamente com a disponibilidade, motivação e dedicação dos 
profissionais na concretização das suas tarefas, sendo esta conclusão passível de verificação nos vários "desabafos" dos (as) Mediadores (as) a que assistimos ao longo das entrevistas, no tratamento das várias questôes: “(...) Nós aqui fazemos o que é o burocrático o que é essencial (...)", "(...) Como eu te dizia, acaba por fazer demasiado trabalho administrativo e falta fazer o outro trabalho que eu acharia complementar (...)”, "(..) o que eu acho que é pior neste papel que estou a desempenhar é a falta de contacto que tenho com eles (...)", "(...) acabo por ter as informaçôes através dos outros colegas, quando as tenho (...)".

Quadro 2. Relacção entre a satisfação e o cumprimento de actividades dos Mediadores/as com o regime de trabalho em "full-time" vs "part-time"

\begin{tabular}{lcc}
\hline \multicolumn{1}{c}{ Sujeito } & $\begin{array}{c}\text { O trabalho desenvolvido vai ao } \\
\text { encontro do pretendido }\end{array}$ & Full-Time/Part-time \\
\hline $\begin{array}{l}\text { Coordenadora } 1 \text { (Instituiçáo } \\
\text { Pública de Formaçáo) }\end{array}$ & Não & Part-time \\
\hline $\begin{array}{l}\text { Coordenador 2 (Instituiçáo } \\
\text { Privada de Formaçáo) }\end{array}$ & Sim & Full-time \\
\hline $\begin{array}{l}\text { Coordenadora } 3 \\
\text { (Escola Pública) }\end{array}$ & Sim & Part-time \\
\hline $\begin{array}{l}\text { Mediadora 1 (Instituiçáo } \\
\text { Pública de Formaçáo) }\end{array}$ & Não & Part-time \\
\hline $\begin{array}{l}\text { Mediadora 2 (Instituiçáo } \\
\text { Pública de Formaçáo) }\end{array}$ & Sim & Part-time \\
\hline $\begin{array}{l}\text { Mediadora 3 (Instituiçáo } \\
\text { Privada de Formaçăo) }\end{array}$ & Sim & Full-time \\
\hline $\begin{array}{l}\text { Mediadora 4 (Instituiçáo } \\
\text { Privada de Formaçáo) }\end{array}$ & Sim & Full-time \\
\hline Mediadora 5 (Escola Pública) & Náo & Part-time \\
\hline
\end{tabular}

O presente quadro ilustra uma maior tendência para a insatisfação, com as actividades desenvolvidas, por parte dos profissionais que trabalham a tempo parcial.

No que concerne ao objectivo central da unidade Aprender com Autonomia, todos os sujeitos, sem excepção, afirmam que esta unidade visa desenvolver a autonomia/auto-estima dos adultos, implementando métodos de trabalho e de estudo individual e de trabalho em equipa e propondo experiências educativas que lhes permitam desenvolver as suas competências de relacionamento interpessoal. Uma das Mediadoras da Instituição Privada de Formação também referiu que a unidade visa fomentar nos formandos momentos de reflexão, contribuindo para melhorar as capacidades de desocultação e construção das suas próprias competências.

Relativamente ao objectivo central da elaboração do Portefólio Reflexivo de Aprendizagens (PRA), apenas colocamos a questão aos/às Coordenadores/as e Mediadores/as que já tiveram oportunidade de trabalhar com EFA Nível Secundário (NS). Depreendemos das suas respostas que o objectivo do PRA é realizar uma reflexão sobre o percurso formativo/ competências adquiridas ao longo da vida e ao longo do curso de formação. Contudo, sentimos da parte destes profissionais alguma insegurança e algum desconforto relativamente ao modo como a construção do PRA pode, ou deve, ser orientada, porque, de acordo com as suas respostas, as consideraçóes da ANQ e a legislação aplicável são muito ambíguas, o 
que leva ao aparecimento de muitas dúvidas por parte dos/as Mediadores/as relativamente à operacionalização desta unidade.

Em ambos os casos (AA/PRA) as Mediadoras lamentaram a falta de normativos mais claros, assim como a falta de materiais pedagógicos, ou de orientaçóes para os construir, que permitisse uma melhor preparação para a dinamização das sessôes.

No que diz respeito à adequação das horas estabelecidas na legislação para AA e para o PRA, a resposta das Mediadoras é unânime e peremptória: " 40 horas são insuficientes para Aprender com Autonomia". Apesar desta posição de princípio, uma das Mediadoras da Instituição Privada de Formação, que trabalha a tempo inteiro, referiu que 40 horas seriam suficientes, desde que não se fizesse mediação nesse horário, reservando-o, apenas, para a dinamização da unidade. Relativamente ao PRA, das três Mediadoras entrevistadas que já trabalharam com níveis secundário, apenas uma afirmou que 85 horas eram suficientes, as outras Mediadoras afirmaram ter dificuldades em cumprir a planificação.

No que concerne ao estabelecimento de relaçóes entre o/a Mediador/a e os formandos, os entrevistados consideraram que talvez seja a tarefa mais importante da mediação, dependendo, em sua opiniáo, quase exclusivamente da qualidade deste relacionamento, o sucesso, ou o fracasso, da generalidade dos/as formandos/as, num determinado curso. A análise dos instrumentos utilizados sugere-nos que o estabelecimento de uma relação de proximidade entre Mediador/a e Formandos/as fundamentada no diálogo e na definição de regras constitui a base do processo de Mediação. Todos os entrevistados atribuíram importância ao diálogo como uma forma de manterem elevado o índice motivacional e de desempenho dos formandos.

No que diz respeito ao estabelecimento de relaçôes de comunicação entre o/a Mediador/a e os formadores/as, as entrevistas revelaram-nos que a relação salutar da equipa formativa e o trabalho com os formandos conduz ao sucesso de um curso. $\mathrm{O}$ Coordenador e as Mediadoras da Instituição Privada de Formação ressalvam a vantagem de existir uma relação de proximidade, mas que as regras têm que ser definidas desde o início, para que todos conheçam liberdades e limites. Uma das Mediadoras afirma que é muito importante acompanhar os formadores/as mais inexperientes, procurando que estes proporcionem formação individualizada de acordo com as características pessoais dos formandos.

Nesta e noutras questôes sentimos que a Mediadora da escola pública se sente descontextualizada e que tem algumas dificuldades em agir conforme a cultura organizacional predominante na instituição. Assim, os dados levam-nos a pensar que na escola a comunicação não flui naturalmente e que, por vezes, a Coordenadora assume posiçóes menos flexíveis devido a algum desconhecimento sobre a temática da Educação/Formação de Adultos.

Em relação às metodologias utilizadas na promoção de um melhor ambiente entre formandos, todos os sujeitos indicam a utilização de dinâmicas de grupo. A par destas estratégias, as Mediadoras entrevistados/as afirmam recorrer a metodologias mais vocacionadas para a gestão de conflitos, referindo, neste domínio, a importância do do recurso ao trabalho em equipa. A análise dos instrumentos confirma, em parte, esta opção, uma vez que algumas Mediadoras optam pela gestão de conflitos em grupo como é o caso das Mediadoras da Instituição Pública de Formação e da escola, enquanto, por outro lado, as Mediadoras da Instituição Privada de Formação preferem tratar dos assuntos a nível individual, deixando para resolver no grupo apenas as questôes que dizem respeito ao conjunto. Verificamos que estas metodologias estão directamente relacionadas com o facto de estes profissionais trabalharem a tempo inteiro ou a tempo parcial. 
No que concerne à promoção de um melhor ambiente entre Formadores e Formandos, concluímos que os sujeitos consideram a imparcialidade como o comportamento ideal a assumir na contribuição para o estabelecimento dessas relaçóes, quer no âmbito dos tempos formativos, quer nos contactos mais informais. De uma forma geral estes profissionais justificam as suas respostas com o estabelecimento de laços entre as partes, sem nunca esquecerem a sua imparcialidade.

Relativamente à ideia que o/as Coordenador/as fazem sobre o trabalho desenvolvido pelas Mediadoras verificamos que a Coordenadora da Instituição Pública de Formação, sente que o trabalho das Mediadoras, muitas vezes, não corresponde ao pretendido e o mesmo se passa com as Mediadoras, que afirmam sentir que o seu trabalho não corresponde ao que se espera, por não possuírem tempo suficiente para o concretizar. A Coordenadora da escola pública afirma que as tarefas desenvolvidas pelos/as Mediadores/as vão ao encontro dos objectivos, contudo, a Mediadora da escola, discorda da sua opiniáo ao atestar que acredita que as suas funçôes náo correspondem ao pretendido devido ao tempo reduzido previsto no seu horário. Em relação à Instituição de Formação Privada, Coordenador e Mediadoras encontram-se de acordo relativamente ao bom desempenho das profissionais responsáveis pela mediaçáo.

No que concerne aos parâmetros de avaliação do trabalho do/a Mediador/a, verificámos que o método de avaliação destes difere de centro para centro/escola. A análise de conteúdo das entrevistas levou-nos a perceber que algumas Mediadoras desconhecem os parâmetros pelos quais são avaliadas e, inclusivamente, desconhecem se existe alguma avaliaçáo formal ao seu desempenho.

As Mediadoras da Instituição de Formação Pública, afirmam não existir avaliação, realizando apenas a sua auto-avaliaçáo. A única coisa de que têm conhecimento é da existência de uma ficha comum a todos os Formadores, que os Formandos preenchem no fim do curso e que depois é tratada estatisticamente, sendo esta informação corroborada pela Coordenadora. As Mediadoras da Instituição Privada de Formação conhecem os parâmetros pelos quais são avaliados/as e conhecem os resultados dessa avaliação, apesar de serem avaliados segundo os mesmos parâmetros que todos os Formadores. Neste caso, quer as Mediadoras, quer o Coordenador afirmam que "a verdadeira avaliaçáo é feita de acordo com o grau de execução física do projecto", ou seja, consoante desistem mais ou menos Formandos. A Mediadora da escola é avaliada segundo os parâmetros da avaliaçáo dos professores.

De acordo com os elementos apresentados concluímos que não existe uma avaliação específica da mediação e dos/as Mediadores/as nas três instituiçôes, uma vez que estes profissionais são avaliados de acordo com os parâmetros aplicados aos Formadores, ou aos Professores, não existindo uma distinção entre estes e os profissionais de mediação.

No que diz respeito ao enquadramento legal, percebemos que todos os sujeitos consideram a legislação inadequada e insuficiente, com excepção do Coordenador da Instituição de Formação Privada que a considera adequada, mas diminuta. A partir da análise das entrevistas verificámos que todos os sujeitos revelam ter dúvidas quanto às práticas, referindo que estas diferem consoante a interpretação de cada um da legislação, causando, em determinadas circunstâncias, algum desconforto. A maior parte dos participantes solicitam a existência de mais informaçáo e de manuais de mediação, referindo que quem elaborou o único existente (apenas está disponível o manual de AA) não possui experiência de campo, o que, segundo os profissionais, contribui para a sua inadequação, servindo de pouco para os auxiliar nas diferentes actividades.

No que diz respeito à última questão de investigação, consciencialização e reflexão crítica do papel do Mediador, a informação recolhida indica-nos que a maior parte do/ 
as Coordenador/as e Mediadoras entrevistado/as, têm vinda a desenvolver uma atitude de reflexão crítica em relação ao papel do Mediador e à sua importância dentro dos Cursos EFA. Percebemos que as Mediadoras entrevistadas afirmam reflectir sobre a sua vida profissional, adquirindo com a experiência um maior conhecimento de si e evoluindo nas suas competências enquanto profissionais e inclusive enquanto pessoas. O paradigma da educaçáo permanente, com maior ou menor incidência, desenvolveu-se na consciência destas profissionais que se preocupam em incrementar o seu trabalho de acordo com ele.

Quadro 3. Evolução da Consciencializaçáo do papel do Mediador

\begin{tabular}{lccc}
\hline \multicolumn{1}{c}{ Sujeito } & Sem evoluçáo & Alguma evoluçáo & Evoluçáo \\
\hline Coordenadora 1 & & $\mathrm{X}$ \\
\hline Coordenador 2 & & $\mathrm{X}$ \\
\hline Coordenadora 3 & $\mathrm{X}$ & $\mathrm{X}$ \\
\hline Mediadora 1 & & \\
\hline Mediadora 2 & $\mathrm{X}$ & $\mathrm{X}$ \\
\hline Mediadora 3 & & $\mathrm{X}$ \\
\hline Mediadora 4 & & \\
\hline Mediadora 5 & $\mathrm{X}$ & \\
\hline
\end{tabular}

Consideramos contudo que o paradigma da Educação de Adultos e a consciencialização da importância da Mediação, ainda não estão muito presentes nos profissionais da escola pública que entrevistámos, verificando-se que a sua experiência pedagógica com o ensino regular interfere com a forma predominante como orientam a sua acção na educaçáo/formação de adultos. Os dados tendem a indicar-nos que os profissionais da escola que integraram a amostra, estão naturalmente formatados pelo ensino regular não possuindo ainda abertura suficiente para a aplicaçáo de novas metodologias no processo de ensino/aprendizagem destinadas a adultos. Relativamente a uma das Mediadoras da Instituição de Formaçáo Pública, verificámos que esta por vezes confunde o seu papel de Mediadora com o de Formadora, uma vez que que desempenha, em simultâneo, as duas funçóes, não possuindo ainda uma consciência completamente estabilizada da sua função, enquanto Mediadora.

\section{Discussáo dos Resultados}

Ao realizarmos o trabalho de investigação focado no entendimento de uma prática educativa inovadora, a mediação nos Cursos EFA, desenvolvemos um percurso de pesquisa, que, longe de se considerar concluído, proporcionou a emergência de alguns elementos significativos para a reflexão, contribuindo desta forma para o aprofundamento da problemática em questáo. Ao longo do caminho heurístico realizado encontramos dados que reforçaram a pertinência das questóes formuladas e que, simultaneamente, fizeram emergir novas interrogaçóes sobre esta actividade. Desta forma consideramos que não podemos concluir este trabalho com a apresentação de um conjunto de respostas conclusivas.

Nos resultados a que foi possível chegar, constatámos a emergência de tensóes, conflitualidades e paradoxos, evidenciando a necessidade de continuar um caminho de reflexão 
e aprofundamento permanente que permitam a elaboração de quadros teóricos e dos normativos possíveis para a orientação da acção. A procura de soluçôes mais pertinentes e adequadas para as questóes que esta nova problemática faz emergir está ainda longe de se considerar solidificada.

Nesta pesquisa, pretendeu-se avaliar, na perspectiva das orientaçóes técnicas e dos/as Coordenadores/as, a necessidade da figura do Mediador, o respectivo perfil, as funçôes previstas e as actividades realizadas. Ao partirmos do pressuposto que a principal função deste profissional é a de mediar relaçóes no processo formativo e, sendo este um indicador válido da sua profissionalidade, intentámos identificar as metodologias utilizadas no estabelecimento de relaçóes interpessoais no processo formativo em que a Mediação se inclui. Mas a avaliação isolada e compartimentada da Mediação não permite, por si só, compreender se existe uma confluência entre aquilo que a instituiçáo espera do papel do Mediador e a forma como percepcionam o desenvolvimento da sua profissionalidade. Para aprofundar a compreensão da atitude perante a Mediação e o Mediador, foi necessário procurar a visão cruzada dos/as Coordenadores/as e dos/as Mediadores/as. Um dos factores determinantes na construção dessa atitude foi a compreensão do sistema de valores e crenças de Coordenadores/as e Mediadores/as, dado que nem todas as acçôes são determinadas por procedimentos normativos, por descriçóes formais de funçôes ou por disponibilidade de recursos, subsistindo um amplo leque de escolhas sobre como responder à exigência da mediação.

A partir do estudo realizado constatámos que o/a Mediador/a exerce um papel fundamental nos Cursos EFA. Percebemos pela análise dos dados, consonantes com as recomendaçóes da ANQ, que a formação base deste profissional inscreve-se, maioritariamente, dentro das Ciências Sociais, mais propriamente nas áreas da Sociologia, Psicologia e Ciências da Educação, não existindo contudo nada na legislação que o defina. Ao certificarmos que não existe uma área de conhecimento específica para o desempenho desta profissão questionámos os entrevistados sobre qual seria o perfil ideal do/a Mediador/a. Dentro de um grupo de respostas muito heterogéneas, conseguimos identificar características comuns evidenciadas pelos sujeitos: idoneidade, sensibilidade, rigor, flexibilidade e capacidade de adaptação. Estas particularidades não são passíveis de reconhecimento logo numa primeira entrevista, assim, apenas podemos depreender que quando um Coordenador recruta um Mediador, o faz de acordo com a sua sensibilidade pessoal, a cultura organizacional do estabelecimento, ou, eventualmente, a empatia estabelecida no processo de recrutamento.

Ao nível das actividades desenvolvidas pelo Mediador concluímos que as divergências existentes dizem respeito a adaptaçóes circunstanciais de cada uma das instituiçôes, recorrentes da sua própria interpretação da lei, das concepçôes do trabalho de formação e do meio em que estão inseridas. Assim, verificamos que Mediadores/as e instituiçôes, na prática, agem em conformidade com o disposto pela entidade reguladora, que os/as contrata, ou à qual pertencem. Constatamos que as actividades do/a Mediador/a são muito de natureza administrativo-burocrático, não existindo muito espaço para uma mediação de natureza mais educativa/formativa. Esta afirmação é corroborada pelas respostas do/as Coordenador/as e das Mediadoras, sendo que apenas uma Mediadora falou na desocultação de competências detidas e no desenvolvimento de novas competências como parte integrante da sua actividade profissional. As profissionais da escola pública compararam a mediação a uma Direcção de Turma, entendendo-a como maioritariamente burocrática. Assim, se formos comparar os resultados dos dados com o quadro teórico de referência, concluímos, 
que o definido pela ANQ e as actividades práticas do/a Mediador/a, se encontram numa margem muito contida de confluência.

Neste sentido parece-nos fundamental repensar os modelos educativos que definem a mediação e construir novos quadros de referência que vão ao encontro de uma mediação pedagógica que vise promover oportunidades de aprendizagem mais abertas e mais completas, consentâneas com um paradigma de Educação e Formação ao Longo da Vida.

No que diz respeito às metodologias utilizadas no estabelecimento de relaçóes interpessoais no processo de Mediação, os dados analisados sugerem a não existência de orientaçôes muito concretas, por parte da ANQ. Relativamente a esta questão, os entrevistados responderam de acordo com a sua experiência e sensibilidade pessoal, alguns manifestaram inclusivamente a dificuldade que tinham em responder a estas perguntas, lamentando não existir mais informação ou formação acerca do tema. Apurámos que estas profissionais gostariam de possuir mais informação por parte da entidade reguladora. Todas sem excepção manifestaram o prazer que têm em trabalhar com pessoas e que essa é a melhor parte da função, não obstante, ficou evidenciado que o estabelecimento de relações interpessoais salutares está directamente relacionado com o trabalho a tempo parcial ou a tempo inteiro.

No decorrer das entrevistas e depois na análise de dados esteve sempre presente na nossa mente a alegria e motivação das Mediadoras que realizavam o acompanhamento dos Formandos e Formadores a tempo inteiro, alegria contrastante com os lamentos das Mediadoras que desempenhavam a sua função a tempo parcial, afirmando que não chegavam a conhecer bem os Formandos e que náo conseguiam realizar as suas tarefas com a profundidade desejada.

Ao nível do desenvolvimento de relaçôes interpessoais, com todos os outros agentes do processo de educação/formação, apesar de não existirem indicaçôes para esta dimensão e de existir unanimidade entre os sujeitos quando referem que estas são questóes do foro mais pessoal, dependentes das características pessoais de cada um, conseguimos depreender que a possibilidade de se estabelecer uma relação próxima fundamentada no diálogo e na definiçấo de regras parece ser a metodologia consensual defendida quer por Coordenador/ as, quer por Mediadoras, para um maior êxito de todo o processo.

Relativamente à última questão da investigaçáo que, na verdade, sintetiza o essencial de todo o processo de pesquisa, sendo, por isso mesmo, transversal às três primeiras, parece-nos termos reunido informação suficiente para afirmar que existem tensões óbvias entre aquilo que a instituição espera do papel do Mediador e a forma como estes profissionais percepcionam a sua profissionalidade. De uma forma geral verificamos que os profissionais que desempenham funçôes a tempo inteiro possuem uma maior sintonia relativamente a esta questão, não se verificando o mesmo nas instituiçóes onde as Mediadoras colaboram a tempo parcial.

Segundo o nosso ponto de vista, a mediação não deveria ser realizada a tempo parcial, dado ser difícil (se não impossível), fazer um acompanhamento do processo de desenvolvimento de competências com profundidade, colaborando com várias instituiçóes ao mesmo tempo. Esta situação parece contribuir para a desmotivação dos/as Mediadores/as, que sentem não corresponder ao pretendido, e para a desmotivação dos formandos, que se sentem pouco acompanhados.

Quando perguntámos ao/às Coordenador/as se a acção das Mediadoras correspondia ao pretendido, todos eles nos responderam afirmativamente, contudo, os dados revelaram-nos, posteriormente, que as suas respostas se fundamentaram em sensibilidades e experiências pessoais. A sua própria análise denunciou que não existem factos para comprovar estas convicçôes. A nossa constatação resulta da confirmação da não existência de uma avaliação 
específica de Mediadores/as, nas três instituiçôes, sendo que os/as Mediadores/as respondem perante parâmetros de avaliaçáo pensados para os Formadores e os Professores. Concluímos então que a avaliação dos/as Mediadores/as, foi descurada pelas instituiçôes da amostra, porque à falta de orientaçóes da ANQ, estes não elaboraram uma norma com parâmetros de avaliação destinados à mediação. Julgamos que este facto contribui para que instituiçôes e profissionais náo consigam apreender a verdadeira dimensão e importância da mediaçáo.

No seguimento destas linhas de pensamento relativamente ao processo de Mediaçáo, arrematamos que este só teria a beneficiar se fosse adoptado um instrumento aferido de avaliação da mesma, podendo os dados resultantes contribuir para um maior desenvolvimento da consciencialização e atitude crítica, das instituiçóes, Mediadores (as) e inclusive da própria entidade reguladora. $\mathrm{O}$ incremento de uma maior consciência e pensamento crítico resultantes deste processo, permitiria a adopçáo de novas metodologias de trabalho e, inclusivamente, poder-se-iam estruturar formaçôes técnicas com vista a colmatar lacunas existentes.

Assim, tendo em conta o cerne da investigação, podemos brevemente concluir que o processo de Mediação, apesar das disparidades de adaptaçáo circunstancial, decorre de uma forma geral conforme o delineado teoricamente pela ANQ, contudo, verificamos que os actuais processos de Mediação nem sempre são convergentes com os modelos teóricos mais relacionados com a educação e formação de adultos. A lógica de uma aprendizagem mediatizada com implicaçóes directas para a vida das pessoas, colocando as competências como organizador central dos processos de mudança, não está interiorizado pela a maioria dos profissionais. Todos eles, com excepção de uma das Mediadoras da Instituição Privada de Formação, quando começaram a falar do objectivo da mediação, fizeram referência à gestão de conflitos, deixando para segundo plano o acompanhamento transformativo dos formandos. Conjecturamos assim que se confunde a Mediação Pessoal e Social dos Cursos EFA, fundamentalmente educativa, com a Mediação Social realizada com grupos socialmente desfavorecidos. Julgamos que esta confusão emerge da novidade que é a Mediação de Cursos EFA, contudo, não desculpabilizamos os profissionais pela desinformação, nem a ANQ pela ausência de uma orientação mais centrada no essencial. Defendemos que a informação e o conhecimento são essenciais e que antes de assumirem qualquer papel, os profissionais têm que se especializar, sendo a ANQ a entidade responsável por formar estes indivíduos.

$\mathrm{O}$ facto de algumas instituições ainda não terem interiorizado o paradigma da Mediação Pessoal e Social dos Cursos EFA, contribui para que o papel dos/as Mediadores/as passe por ser mais administrativo-burocrático, do que deveria, deixando para segundo plano outras dimensóes. Concluímos que, apesar da Mediação ser encarada de uma forma semelhante e responsável, pelas três instituiçôes, pode constatar-se a existência de diferenças assinaláveis nas actividades e metodologias utilizadas. Tal facto deve-se, em parte, à visão da instituição e ao posicionamento dos responsáveis perante estas problemáticas, bem como à forma como todos encaram a educação/formação de adultos. É importante assinalar que isto poderia não ser, necessariamente, uma debilidade. Promover a autonomia das instituiçóes e a possibilidade de cada uma construir, com os seus quadros orientadores, uma cultura própria de educação e formação de adultos poderia, até, ser um sinal de vitalidade. Para isso, contudo, seria necessário promover uma formação de base e um hábito de reflexão e melhoria contínua que nos parece, neste momento, muito longe de todas estas práticas.

Finalizamos com a crença de que a mediação, como técnica pedagógica de grande relevância, contribui para uma maior tomada de consciência das características e das competências pessoais, sociais e profissionais dos indivíduos, assim como contribui para o 
reforço das suas capacidades para a construção mais adequada de projectos profissionais e de vida. Constitui-se, assim, como um processo promotor do desenvolvimento das pessoas, tornando-as mais interessadas e comprometidas com a realidade, mais confiantes, informadas e participativas, factores que possivelmente potenciarão a sua capacidade e vontade de se tornarem agentes de mudanças sociais.

\section{Bibliografia}

Alcoforado, J. L. (2000). Educação de Adultos e Trabalho. Tese de Dissertação de Mestrado, Coimbra: FPCE UC. Antunes, M. C. (2007). Educação de Adultos e Intervenção Comunitária. Lisboa: Almedina.

Bonafé-Schmitt, J.-P., et al. (1999). Les médiations, la mediation. Ramonville Saint-Agne: Editions Erès.

Boldú, M., R. M. C. et al. (2003). Introducción a la mediación. Mediación familiar y social en diferentes contextos. Valencia: Nau Llibres.

Cardinet, Annie (1995). Pratiquer la médiation en pédagogie. Paris: Dunod.

Carneiro, R. (2001). Fundamentos de Educação e Aprendizagem. Vila Nova de Gaia: Fundaçáo Manuel Leão.

Faure, E. et al. (1972). Learning to be. The world of education today and tomorrow. Paris: UNESCO.

Finger, M.; Asún, J. M. (2003). A Educação de Adultos numa Encruzilhada. Porto: Porto Editora.

Freire, P. (2003). Pedagogia do Oprimido. São Paulo: Paz e Terra.

Freire, P. (1977). Educação Politica e conscientização. Lisboa: Ed. Livraria Sá da Costa.

Freire, P. (1998). Pedagogia da Autonomia - saberes necessários à prática educativa. São Paulo: Ediçóes Paz e Terra.

Gadotti, M. (2001). Educar adultos hoje na perspectiva de Paulo Freire. Revista Portuguesa de Pedagogia, ano $35, n^{\circ} 1,31-40$.

Jarvis, P. (2001). O futuro da educação de adultos na sociedade de aprendizagem. Revista Portuguesa de Pedagogia, Ano 35, $n^{\circ} 1,13-30$.

Martin, J. A. San (2003). La Mediación Escolar - un Camino Nuevo para la Gestión del Conflicto escolar. Madrid: Editorial CCS.

Melo, A. et al. (1998). Uma aposta educativa na participação de todos. Documento estratégico para o desenvolvimento da educaçấo de adultos. Lisboa: Ministério da Educação.

Moore, C. W. (1998). Como funciona a mediação. O processo de mediação: estratégias práticas para a resolução de conflitos. Porto Alegre: Artmed.

Pineau, G. (1998). Accompagnements et Histoire de Vie. Paris: l'Harmattan.

Rogers, C. (1970). Tornar-se Pessoa. Lisboa: Moraes Ediçōes.

Ruggiero, R. (1988). Enciclopédia Einaudi. Vol. 10, Porto: Imprensa Nacional - Casa da Moeda.

Seijo, J. C. T. (coord.) (2003). Mediação de Conflitos em Instituiçōes Educativas. Manual para Formação de Mediadores. Porto: Ediçōes Asa.

Torremorell, M. C. B. (2008). Cultura de Mediação e Mudança social. Porto: Porto Editora.

Vezzulla, J. C. (2004). Mediação, Teoria e Prática, Guia para Utilizadores e Profissionais. Lisboa: Agora Publicaçôes. Vygotsky, L. (1988). Pensamento e Linguagem. São Paulo: Martins Fontes.

\section{Legislaçáo:}

Diário da República (2008), Portaria 230/2008 de 7 de Março, artigo 25; Diário da República, 2.a série N. $99-23$ de Maio de 2008. ANQ.

\section{Webgrafia:}

Freitas, M.. A Educação e Formação de Adultos: um caminho para a elevação da escolaridade e da empregabilidade em Portugal - UFAL. Disponível em: http://www.anped.org.br/reunioes/32ra/arquivos/trabalhos/GT18-5121-Int.pdf. Consultado em: 2/04/2010.

Melo, A.. Em Portugal: uma nova vontade política de relançar a Educação e Formação de Adultos?. Disponível em: www.anped.org.br/reunioes/26/outrostextos/sealbertomelo.rtf. Consultado em: 5/03/2010.

Porquê a Iniciativa Novas Oportunidades. Disponível em: http://www.novasoportunidades.gov.pt/np4/7.html.. Consultado em: 7/4/2010.

www.anq.gov.pt/default.aspx , consultado dia 10/01/2010 
Série Documentos

Imprensa da Universidade de Coimbra

Coimbra University Press

2011

- U

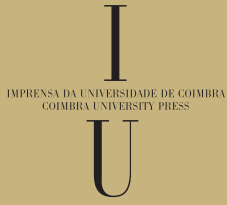

